\title{
Prevalence and trends of benzodiazepine use among Veterans Affairs patients with posttraumatic stress disorder, 2003-2010
}

\author{
Eric J. Hawkins a,b,d,*, Carol A. Malte ${ }^{\mathrm{a}, \mathrm{b}}$, Zac E. Imel ${ }^{\mathrm{e}}$, Andrew J. Saxon ${ }^{\mathrm{b}, \mathrm{c}}$, Daniel R. Kivlahan ${ }^{\mathrm{a}, \mathrm{b}, \mathrm{d}}$ \\ a Health Services Research and Development, VA Puget Sound Health Care System, Seattle, WA, United States \\ ${ }^{\mathrm{b}}$ Center of Excellence in Substance Abuse Treatment and Education, VA Puget Sound Health Care System, Seattle, WA, United States \\ ${ }^{c}$ Department of Psychology, University of Washington, Seattle, WA, United States \\ d Department of Psychiatry and Behavioral Sciences, University of Washington, Seattle, WA, United States \\ e Department of Educational Psychology, University of Utah, Salt Lake City, UT, United States
}

\section{A R T I C L E I N F O}

\section{Article history:}

Received 30 September 2011

Received in revised form 4 January 2012

Accepted 7 January 2012

Available online 2 February 2012

\section{Keywords:}

Trends in benzodiazepine use

Posttraumatic stress disorder

Opioid analgesics use

\begin{abstract}
A B S T R A C T
Background: Although the Veterans Affairs and Department of Defense (VA/DoD) clinical guidelines for management of posttraumatic stress disorder (PTSD) recommend against routine benzodiazepine use, little is known about the trends and clinical and prescription profiles of benzodiazepine use since these guidelines were released in 2004.

Methods: This retrospective study included 64,872 patients with a PTSD diagnosis received from care at facilities in VA Northwest Veterans Integrated Service Network (VISN 20) during 2003-2010. Annual prevalence of any use was defined as any prescription for benzodiazepines, and long-term use was defined as $>90$ days' supply, in a year. Gender-specific logistic regressions were fit to estimate any and long-term benzodiazepine use, test for linear trends over 8-years and explore factors associated with trends.

Results: The trend of age-adjusted benzodiazepine use over 8-years rose significantly from 25.0 to $26.8 \%$ among men and 31.2 to $38.8 \%$ among women. Long-term use in men and women increased from 15.4 to $16.4 \%$ and 18.0 to $22.7 \%$, respectively. Comorbid psychiatric and alcohol use disorders (AUD) were associated with a greater increase in long-term use of benzodiazepines. In $2010,61 \%$ of benzodiazepine users received $>90$ days' supply. Among those prescribed benzodiazepines long-term, $11 \%$ had AUD and $47 \%$ were also prescribed opioids long-term.

Conclusion: Despite VA/DoD clinical guidelines recommending against routine use of benzodiazepines for PTSD, the adjusted prevalence of long-term use increased among men and women with PTSD in VISN 20. Widespread concomitant use of benzodiazepines and opioids suggests risk management systems and research on the efficacy and safety of these medications are needed.
\end{abstract}

Published by Elsevier Ireland Ltd.

\section{Introduction}

Posttraumatic stress disorder (PTSD) is one of the most common mental health conditions among patients in the Veterans Affairs (VA) health care system and is associated with significant morbidity (Jacobsen et al., 2001; Keane and Kaloupek, 1997) and mortality (Boscarino, 2006). Approximately 41\% of all VA patients and 52\% of those from Operations Enduring Freedom and Iraqi Freedom (OEF/OIF) with a mental health disorder have a documented PTSD diagnosis (Petrakis et al., 2011).

Several clinical guidelines (American Psychiatric Association, 2004; Baldwin et al., 2005), including the current VA/Department of

* Corresponding author at: VA Puget Sound Health Care System - Seattle Division (S116ATC), 1660 S. Columbian Way, Seattle, WA 98108, United States. Tel.: +1 206764 2743; fax: +1 2067642293 .

E-mail addresses: Eric.Hawkins@va.gov, emhawkins_9@msn.com (E.J. Hawkins).
Defense (DoD) clinical guideline, recommend behavioral therapies and selective serotonin reuptake inhibitors (SSRIs) for treatment of PTSD and caution against routine use of benzodiazepines to manage PTSD symptoms, citing risks associated with their use and lack of evidence supporting improvements in PTSD symptoms (The Management of Post-Traumatic Stress Working Group, 2010; Stein et al., 2006). Despite these recommendations benzodiazepines are commonly prescribed (31\% in fiscal year 2009; Lund et al., 2011) among VA patients diagnosed with PTSD (Mohamed and Rosenheck, 2008). Specific clinical indications for benzodiazepine use among patients with PTSD are unknown, but benzodiazepines have a quick onset and provide rapid relief of anxiety (Hoffman and Mathew, 2008) and insomnia (Riemann and Perlis, 2009), symptoms common in patients with PTSD.

There are several contraindications and potential risks associated with routine benzodiazepine use in patients with PTSD. Administration of benzodiazepines in patients with early posttraumatic stress symptoms may be associated with the development of 
PTSD (Davydow et al., 2008; Gelpin et al., 1996) and may weaken the treatment effects of exposure therapies for PTSD (van Minnen et al., 2002). Furthermore, due to their abuse or dependence potential, benzodiazepines are contraindicated because of high lifetime rates of comorbid substance use disorders (SUD) among patients with PTSD (Longo and Johnson, 2000; Lader, 1999; Jacobsen et al., 2001). Benzodiazepine use is also associated with increased risk of withdrawal symptoms after discontinuation (Lader, 1999, 2011), completed suicide among depressed VA patients (Pfeiffer et al., 2009), as well as motor vehicle crashes (Smink et al., 2010), falls (Woolcott et al., 2009), hip fractures (Cumming and Le Couteur, 2003) and cognitive disturbance (Barker et al., 2004) among the elderly. A growing concern is the contribution of benzodiazepines to the national rise in opioid-related poisoning deaths (Warner et al., 2009) and to emergency department visits for nonmedical use of prescriptions and drug-related suicide attempts. In 2006, benzodiazepines were involved in $17 \%$ of fatal opioid poisonings (Warner et al., 2009). From 2004 to 2008, drug-related emergency department visits for nonmedical use of benzodiazepines and benzodiazepine-related suicide attempts increased 89.0 and 51\%, respectively (Substance Abuse and Mental Health Services Administration, 2011).

Population-based studies from several countries suggest rates of benzodiazepine use range from 3 to 17\% (Cunningham et al., 2010; Lagnaoui et al., 2004; Petitjean et al., 2007), with rates typically higher among older (22.5-32.0\%; Cunningham et al., 2010; Petitjean et al., 2007) than younger persons and 1.5-2 times higher among women than men (Cunningham et al., 2010; Lagnaoui et al., 2004; Petitjean et al., 2007). Rates of long-term benzodiazepine use, defined as $>90$ days, typically range from 2 to $4 \%$ (Cunningham et al., 2010; Zandstra et al., 2002). Although higher rates of any and long-term benzodiazepine use are associated with psychiatric disorders such as PTSD (Lund et al., 2011; Valenstein et al., 2004), little is known about the gender-specific prevalence and trends of benzodiazepine use among VA and non-VA patients diagnosed with PTSD. Furthermore, despite the potential of their pharmacological interaction leading to respiratory depression and death (White and Irvine, 1999), there is surprisingly little information on the co-prescription of benzodiazepines and opioids among those with PTSD.

In order to assess trends in benzodiazepine use among patients in the VA since the initial release of the clinical practice guideline in 2004, we estimate the annual prevalence of any and long-term benzodiazepine use, and examine the clinical patterns and trends in benzodiazepine use over an 8-year period (2003-2010) among a sample of VA outpatients diagnosed with PTSD, with a particular interest in gender- and age-specific trends. We also describe high risk behaviors, such as concomitant use of opioid analgesics and presence of alcohol use disorders, among veterans prescribed benzodiazepines, and explore factors associated with benzodiazepine use in this population.

\section{Methods}

\subsection{Study setting and data collection}

The setting for this study is the VA Northwest Veterans Integrated Service Network (VISN 20), which includes Washington, Oregon, Idaho, and Alaska. Administrative medical record data were extracted from the VISN 20 Data Warehouse, which contains the electronic health records of VA health care facilities in VISN 20 Study approval was obtained from the VA Institutional Review Board at the VA Puget Sound Health Care System.

\subsection{Study sample}

All veterans who received health care from one of the VA facilities in VISN 20 during fiscal years 2003-2010 were eligible for study participation. Patients included in the study were (1) age 18 or older, and (2) received a primary or secondary diagnosis of posttraumatic stress disorder (PTSD) at $\geq 1$ outpatient visit(s) or inpatient discharge(s) from a VISN 20 facility during 2003-2010 ( $N=64,872)$. Patients were included in analyses for a given fiscal year if a PTSD diagnosis was documented in their electronic medical record for that year, and those with PTSD diagnoses in multiple years were included in each fiscal year that a PTSD diagnosis was documented.

\subsection{Measures}

2.3.1. Benzodiazepine measures. VA pharmacy data was limited to outpatient prescription medication data, which includes the type and quantity of medication prescribed, dose, number of days' supply, physicians' instructions, and date the prescription was released from the pharmacy. Oral benzodiazepines considered in this study included aprazolam, chlordiazepoxide, clonazepam, clorazepate, diazepam, estazolam, flurazepam, halazepam, lorazepam, oxazepam, prazepam, quazepam, temazepam, and triazolam.

Prevalence. The two primary measures of benzodiazepine use included the (1) annual prevalence of any benzodiazepine use defined as any filled prescription for benzodiazepines during a year, and (2) long-term benzodiazepine use defined as >90 total days' supply of benzodiazepine prescriptions filled in a year (Petitjean et al. 2007; Valenstein et al., 2004).

Days' supply. The total days' supply of benzodiazepines received during a year was calculated by summing the days' supply from benzodiazepine prescriptions filled during the fiscal year. This is referred to as the "as-prescribed" approach and assumes that patients take all prescribed benzodiazepines at the maximum dose and schedule prescribed by their providers (Bohnert et al., 2011; Valenstein et al., 2004). If patients filled a subsequent prescription but had medication remaining from the prior fill based on the schedule prescribed, total days supply was calculated as follows: (1) when prescriptions overlapped on $<50 \%$ of days, the days' supply of the overlapped prescriptions were added independently; (2) when prescriptions overlapped on $\geq 50 \%$ of days, the days' supply was the difference between the initial release date of the prior fill and the final end date of all subsequent overlapping prescriptions (assumes overlapping prescriptions were intended to increase the dose rather than days' supply of benzodiazepines; Valenstein et al., 2004). To further characterize the duration of benzodiazepine treatment episodes, total days' supply of benzodiazepines for a fiscal year was categorized into five groups: (1) 1-30 days, (2) 31-90 days, (3) 91-180 days, (4) 181-270 days and (5)>270 days.

Mean dose. The mean prescribed benzodiazepine dose per day was expressed in diazepam-equivalent milligrams (Chouinard, 2004; Galanter and Kleber, 2008) and determined by dividing the total quantity of medication released by the days' supply. To further characterize the dosage distribution, the mean prescribed dose per day was also categorized into five groups: (1) 0-10 mg, (2) $11-20 \mathrm{mg}$, (3) $21-30 \mathrm{mg}$, (4) 31-40 $\mathrm{mg}$ and (5) >40 mg. Benzodiazepine doses between 10 and $40 \mathrm{mg}$ diazepam equivalents per day typically represent the therapeutic range (Physicians Desk Reference, 2011).

2.3.2. Opioid analgesic measures. The above procedures were used to calculate the duration of opioid analgesic episodes. Opioid analgesics considered in this study included oral codeine, morphine, oxycodone, hydrocodone, oxymorphone, propoxephene, hydromorphone, levorphanol, meperidine, methadone (tablets only to exclude unit dosing received in methadone maintenance programs), tramadol, pentazocine, fentanyl and transdermal fentanyl. Any use was defined as any prescription for opioids filled in a year, and long-term use was defined as $>90$ days' supply in a year (Edlund et al., 2007, 2010).

2.3.3. Patient characteristics and medical facility. We selected covariates that have been associated with benzodiazepine use and/or PTSD and were available in VA administrative data. Socio-demographic covariates included age, gender, marital status, and VA disability pension. Race was not used because of a large amount of missing data and historically low agreement between VA administrative and selfreported sources of race (Kressin et al., 2003).

Substance use disorders (excluding tobacco), mental health disorders, and medical diagnoses documented in the same fiscal year as the PTSD diagnosis were identified using International Classification of Diseases, Ninth Revision Clinical Modification Codes (ICD-9-CM). Patients with substance use disorders were further classified into three mutually exclusive groups: (1) alcohol use disorder only; (2) drug use disorder only; (3) alcohol and drug use disorders. Psychiatric comorbidity was determined by classifying patients as receiving depressive, bipolar, anxiety and/or psychotic disorder diagnoses and summing the total number of diagnostic groups for each patient; patients then were categorized into three mutually exclusive categories (1) 0 comorbid diagnoses, (2) 1 comorbid diagnosis, and (3) $\geq 2$ comorbid diagnoses.

Epilepsy, sleep disorders, alcohol and drug withdrawal diagnoses represent potential indications for benzodiazepine use and were identified from ICD-9-CM codes to further characterize the sample (see Table 1 for ICD-9-CM codes). Epilepsy diagnosis was rare and thus is not presented here. Because pain disorders also have been associated with benzodiazepine use (Liu et al., 2010), back pain, neck pain, arthritis/joint pain, headache/migraine and neuropathy diagnoses were used to calculate a binary measure (yes/no) of pain (Sullivan et al., 2008). A modified version of the Charlson Comorbidity Index (CCI; Charlson et al., 1987) was used to calculate a measure of medical comorbidity for each year. CCI scores are calculated from 
Table 1

Demographic and diagnostic characteristics of patients with documented PTSD and any and long-term use of benzodiazepines for 2003 and 2010.

\begin{tabular}{|c|c|c|c|c|c|c|}
\hline \multirow[t]{2}{*}{ Characteristic } & \multicolumn{3}{|l|}{ Any benzodiazepine use } & \multicolumn{3}{|c|}{ Long-term ${ }^{\mathrm{a}}$ benzodiazepine use } \\
\hline & FY2003( $n=4327) n(\%)$ & $\mathrm{FY} 2010(n=8901) n(\%)$ & & FY2003(n= 2637)n (\%) & $\mathrm{FY} 2010(n=5399) n(\%)$ & \\
\hline Sex & & & $* * *$ & & & $* * *$ \\
\hline Men & $3848(88.9)$ & $7638(85.8)$ & & $2365(89.7)$ & $4661(86.3)$ & \\
\hline Women & $479(11.1)$ & $1266(14.2)$ & & $272(10.3)$ & $738(13.7)$ & \\
\hline Age (year) & & & $* * *$ & & & *** \\
\hline$<35$ & $132(3.1)$ & $1178(13.2)$ & & $58(2.2)$ & $447(8.3)$ & \\
\hline $35-44$ & $341(7.9)$ & $1015(11.4)$ & & $188(7.1)$ & $534(9.9)$ & \\
\hline $45-54$ & $1514(35.0)$ & $1324(14.9)$ & & $940(35.7)$ & $825(15.3)$ & \\
\hline $55-64$ & $1851(42.7)$ & $4186(47.0)$ & & $1134(43.0)$ & $2794(51.8)$ & \\
\hline$\geq 65$ & $489(11.3)$ & $1201(13.5)$ & & $317(12.0)$ & $799(14.8)$ & \\
\hline Marital status & & & $* * *$ & & & ${ }^{*}$ \\
\hline Married or widowed & $2473(57.2)$ & $4904(55.1)$ & & $1548(58.7)$ & $3066(56.8)$ & \\
\hline Separated or divorced & $1480(34.2)$ & $2966(33.3)$ & & $862(32.7)$ & $1793(33.2)$ & \\
\hline Never married & $367(8.5)$ & $989(11.1)$ & & $225(8.5)$ & $520(9.6)$ & \\
\hline Unknown & $7(0.2)$ & $45(0.5)$ & & $2(0.1)$ & $20(0.4)$ & \\
\hline VA disability $(\geq 50 \%)$ & $3518(81.3)$ & $6347(71.3)$ & ${ }^{* * *}$ & $2185(82.9)$ & $4007(74.2)$ & ${ }^{* * *}$ \\
\hline \multicolumn{7}{|c|}{ Common substance use disorder diagnoses } \\
\hline Alcohol use disorders & $637(14.7)$ & $1265(14.2)$ & ns & $322(12.2)$ & $617(11.4)$ & ns \\
\hline Cannabis use disorders & $168(3.8)$ & $418(4.7)$ & * & $89(3.4)$ & $222(4.1)$ & ns \\
\hline Cocaine use disorders & $82(1.9)$ & $134(1.5)$ & ns & $41(1.6)$ & $62(1.2)$ & ns \\
\hline Opiate use disorders & $107(2.5)$ & $309(3.5)$ & $* *$ & $58(2.2)$ & $177(3.3)$ & ** \\
\hline Other drug use disorders ${ }^{\mathrm{b}}$ & $228(5.3)$ & $538(6.0)$ & ns & $119(4.5)$ & $282(5.2)$ & ns \\
\hline Any common alcohol or drug disorder & $774(17.9)$ & $1657(18.6)$ & ns & $407(15.4)$ & $864(16.0)$ & ns \\
\hline \multicolumn{7}{|l|}{ Psychiatric disorder diagnoses } \\
\hline Depressive disorders & $2505(57.9)$ & $5729(64.3)$ & $* * *$ & $1502(57.0)$ & $3502(64.9)$ & $* * *$ \\
\hline Bipolar disorders & $459(10.6)$ & $927(10.4)$ & ns & $294(11.2)$ & $593(11.0)$ & ns \\
\hline Anxiety disorders & $1064(24.6)$ & $2661(29.9)$ & $* * *$ & $671(25.5)$ & $1632(30.3)$ & $* * *$ \\
\hline Psychotic disorders & $396(9.2)$ & $570(6.4)$ & $* * *$ & $269(10.2)$ & $383(7.1)$ & ${ }^{* * *}$ \\
\hline Count of psychiatric diagnoses & & & $* * *$ & & & $* * *$ \\
\hline None & $1217(28.1)$ & $1995(22.4)$ & & $742(28.1)$ & $1162(21.5)$ & \\
\hline 1 & $2121(49.0)$ & $4561(51.2)$ & & $1267(48.1)$ & $2744(51.4)$ & \\
\hline$\geq 2$ & $989(22.9)$ & $2348(26.4)$ & & $628(23.8)$ & $1463(27.1)$ & \\
\hline Medical comorbidity (Charlson score) & & & * & & & * \\
\hline 0 & $2359(54.5)$ & 4973(55.9) & & $1429(54.2)$ & $2826(54.2)$ & \\
\hline 1 & $1072(24.8)$ & $2907(22.9)$ & & $664(25.2)$ & $1326(24.6)$ & \\
\hline$\geq 2$ & $896(20.7)$ & $1024(21.3)$ & & $544(20.6)$ & $1247(23.1)$ & \\
\hline \multicolumn{7}{|l|}{ Other diagnoses } \\
\hline Pain $^{c}$ & $2777(64.2)$ & $6368(71.5)$ & ${ }^{* * *}$ & $1705(64.7)$ & $3911(72.4)$ & *** \\
\hline Alcohol or drug withdrawal $^{\mathrm{d}}$ & $75(1.7)$ & $162(1.8)$ & ns & $25(0.9)$ & $61(1.1)$ & ns \\
\hline Sleep disorders ${ }^{\mathrm{e}}$ & $537(12.4)$ & $1956(22.0)$ & ${ }^{* * *}$ & $320(12.1)$ & $1142(21.2)$ & $* * *$ \\
\hline \multicolumn{7}{|l|}{ Opioid prescriptions filled ${ }^{\mathrm{f}}$} \\
\hline Any use & $2113(48.8)$ & $5227(58.7)$ & $* * *$ & $1372(52.0)$ & $3407(63.1)$ & *** \\
\hline Long-term use $\mathrm{a}^{\mathrm{a}}$ & $1217(28.1)$ & $3403(38.2)$ & ${ }^{* * *}$ & $877(33.3)$ & $2514(46.6)$ & ${ }^{* * *}$ \\
\hline
\end{tabular}

ns, not significant.

a Long-term use defined as $>90$ days with prescribed doses in the fiscal year.

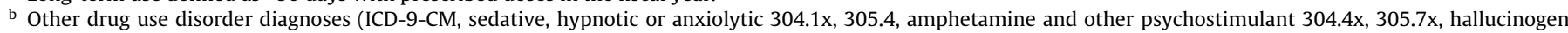
$304.5 \mathrm{x}, 305.3 \mathrm{x}$, other specified drug use 304.6x, 304.8x, 305.9x, unspecified drug use 304.9x, 305.9x).

c Pain diagnoses (ICD-9-CM, back pain 721.3x-721.9x, 722.2x, 722.30, 722.70, 722.80, 722.90, 722.32, 722.72, 722.82, 722.92, 722.33, 722.73, 722.83, 722.93, 724.xx, 737.1,

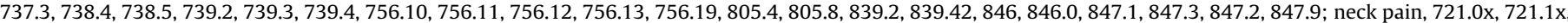

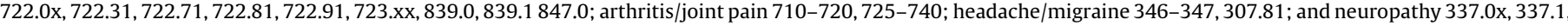

$337.2 x, 337.3,337.9,356 . x, 357.1-357.7,357.8 x, 357.9)$.

d Alcohol and drug withdrawal diagnoses (ICD-9-CM, 291.0, 292.0).

e Sleep disorder diagnoses (ICD-9-CM, 307.40-307.42, 307.47, 307.48, 307.50, 780.50, 780.52, 780.55, 780.56, 780.59)

f Methadone prescriptions were limited to tablets only to exclude unit dosing received in methadone maintenance programs.

${ }^{*}<0.05$.

** $<0.01$

$* * * * 001$.

ICD-9-CM codes that identify 17 health conditions (Quan et al., 2005), with higher scores reflecting greater severity. CCI scores were assigned to three groups: 0 , $1, \geq 2$

A coded medical facility variable, representing eight medical facility campuses that comprise the VA health care system in VISN 20, was also obtained. This variable was used in analyses to adjust for variations among medical centers.

\subsection{Analyses}

Descriptive statistics were generated to compare the demographic, diagnostic and medication profiles of patients with any and long-term use of benzodiazepines in 2003 and 2010. Because gender and age are consistently associated with benzodiazepine use, all analyses were run for men and women separately and adjusted for age (Cunningham et al., 2010; Petitjean et al., 2007; Zandstra et al., 2002). Annual prevalence of any and long-term use of benzodiazepines were estimated using logistic regression models, with age modeled as a continuous variable and year a categorical variable. Linear trends of any and long-term benzodiazepine use over the 8-year period were tested using age-adjusted and age-specific logistic regression models, with year modeled as a continuous variable and adjustment for medical and psychiatric comorbidity. To explore factors potentially associated with changes in benzodiazepine use, differences in linear trends of any and long-term use of benzodiazepines were examined using logistic regression models which included age, medical, psychiatric and substance use disorder comorbidity and their interaction terms with fiscal year. Additionally, medical facility was included as a categorical variable to adjust for variation among facilities. Testing for main effects of site and trends by site were beyond the scope of the study Because there were few women older than 65, the two oldest age groups of women (55-64 and $\geq 65$ ) were collapsed into one group for these analyses. Robust standard errors were used to estimate adjusted prevalence and corresponding $95 \%$ confidence intervals (CI). All analyses were performed using Stata version 11.0 (StataCorp. 2007). 
Table 2

Prescription profiles among PTSD patients with any use and long-term use of benzodiazepines for 2003 and 2010.

\begin{tabular}{|c|c|c|c|c|c|c|}
\hline \multirow[t]{2}{*}{ Prescription profiles } & \multicolumn{3}{|c|}{ Any benzodiazepine use } & \multicolumn{3}{|c|}{ Long-term ${ }^{\mathrm{a}}$ benzodiazepine use } \\
\hline & FY2003 $(N=4327)$ & FY2010 $(N=8904)$ & $p$-Value & FY2003 $(N=2637)$ & FY2010 $(N=5399)$ & $p$-Value \\
\hline Days supply (category), \% & & & ns & & & ns \\
\hline $1-30$ days & 21.1 & 21.5 & & & & \\
\hline $31-90$ days & 17.7 & 17.6 & & & & \\
\hline $91-180$ days & 17.7 & 18.3 & & 29.5 & 29.5 & \\
\hline $181-270$ days & 14.5 & 14.4 & & 23.7 & 23.8 & \\
\hline$>270$ days & 28.4 & 27.9 & & 46.3 & 46.1 & \\
\hline Average days supply, mean (SD) & $175.3(133.0)$ & $174.4(133.2)$ & ns & $261.2(98.1)$ & $260.8(98.8)$ & ns \\
\hline \multicolumn{7}{|l|}{ Prescribed dose/day ${ }^{\mathrm{b}}$ (category), \% } \\
\hline $0-10 \mathrm{mg}$ & 48.8 & 51.7 & & 37.6 & 40.4 & \\
\hline $10-20 \mathrm{mg}$ & 31.5 & 30.2 & & 35.8 & 35.0 & \\
\hline $20-30 \mathrm{mg}$ & 11.5 & 11.5 & & 15.6 & 15.8 & \\
\hline $30-40 \mathrm{mg}$ & 4.8 & 4.3 & & 6.6 & 5.8 & \\
\hline $40+m g$ & 3.4 & 2.3 & & 4.5 & 3.1 & \\
\hline Average prescribed dose ${ }^{\mathrm{b}}$ per day, mg, mean (SD) & $15.0(11.8)$ & $14.3(10.6)$ & $<0.001$ & $17.1(12.5)$ & $16.2(11.1)$ & $<0.01$ \\
\hline
\end{tabular}

ns, not significant; SD, standard deviation.

a Long-term use defined as $>90$ days with prescribed doses in the fiscal year.

b Dose is expressed in diazepam-equivalent milligrams using conversion factors suggested from sources in the literature.

\section{Results}

\subsection{Patient characteristics}

Table 1 summarizes measured demographic and diagnostic characteristics of patients diagnosed with PTSD and prescribed benzodiazepines during fiscal years 2003 and 2010. Both any use and long-term use of benzodiazepines were more common in 2010 than 2003 for women, all age groups except those aged 45-54, and patients with co-occurring medical and depressive, anxiety, sleep and pain disorders.

\subsection{Prescription profiles}

For 2003 and 2010 lorazepam and clonazepam were the most commonly prescribed benzodiazepines followed by temazepam, diazepam, and alprazolam. From Table 2, approximately $61 \%$ of benzodiazepine users in 2003 and 2010 were prescribed long-term supplies of benzodiazepines. Mean days' supply for any and longterm benzodiazepine use for 2003 and 2010 were stable. Prescribed daily doses among patients with any benzodiazepine use were in the $0-10 \mathrm{mg}$ diazepam equivalents range for 48.8 and $51.7 \%$ of patients in 2003 and 2010, respectively, and greater than the typical therapeutic range of $0-40 \mathrm{mg}$ in $3.4 \%$ of patients in 2003 and $2.3 \%$ of patients in 2010. Prescribed daily doses for the majority of longterm benzodiazepine users fell within the $0-20 \mathrm{mg}$ range, while approximately $4.5 \%$ of long-term users in 2003 and 3.1\% in 2010 received a dose exceeding $40 \mathrm{mg}$ per day. From 2003 to 2010, there was a small ( $<1 \mathrm{mg}$ diazepam equivalent) statistically significant decrease in the mean prescribed dose per day of benzodiazepines for all users and long-term users.

\subsection{Prevalence and overall trends in any and long-term benzodiazepine use}

The age-adjusted prevalences of any use and long-term use of benzodiazepines are presented in Tables 3 and 4 for fiscal years 2003-2010 among men and women with PTSD, respectively. Among men, the age-adjusted prevalence of any benzodiazepine use increased modestly from $25.0 \%$ (95\% CI: $24.4-25.7$ ) to $26.8 \%$ (95\% CI: 26.2-27.3), whereas long-term use rose modestly from 15.4\% (95\% CI: $14.8-15.9$ ) to $16.4 \%$ (95\% CI: 16.0-16.9). For women, the age-adjusted prevalence of any benzodiazepine use rose from $31.2 \%$ (95\% CI: $28.9-33.5$ ) to $38.8 \%$ (95\% CI: 37.1-40.5), and longterm use increased from $17.8 \%$ (95\% CI: $15.9-19.8)$ to $22.6 \%$
(95\% CI: 21.2-24.0). For men overall there was a small, significant linear increase in the adjusted prevalences of any and long-term benzodiazepine use from 2003 to 2010 after adjustment for age, medical and psychiatric comorbidity [any use: AOR=1.01 (1.01-1.02) and long-term use: AOR=1.01 (1.01-1.02) respectively]. Among women the adjusted prevalence of any use of benzodiazepines increased significantly from 2003 to 2010 $[\mathrm{AOR}=1.04(1.03-1.06)]$, as did the adjusted prevalence of longterm benzodiazepine use $[\mathrm{AOR}=1.05(1.03-1.07)]$. Table 3 suggests that among men, increases in any and long-term use of benzodiazepines were limited to those younger than 35 and those aged 55-64, whereas significant increases were seen in all age groups among women, with the exception of those $\geq 65$.

\subsection{Exploratory analyses of trend differences in any and long-term benzodiazepine use}

Factors associated with changes in any use and long-term use of benzodiazepines from 2003 to 2010 are presented in Table 5. Consistent with age-specific analyses above, long-term benzodiazepine use over the 8-year period increased more among men younger than 35 than among men in the older age groups, with the exception of men aged 55-64. The increase in long-term benzodiazepine use over the 8 years in men with 1 and $\geq 2$ comorbid psychiatric disorders was significantly greater than men with PTSD only. There was also a small, linear increase in long-term benzodiazepine use among men with alcohol use disorders only compared to those with no substance use disorders. Results for models of any benzodiazepine use among other subgroups of men were largely similar with two exceptions. A greater increase in any benzodiazepine use was also found among men with alcohol and drug use disorders compared to men without comorbid substance use disorders and the increase in any benzodiazepine use among men younger than 35 was greater than all groups of men aged 45 and older. No reliable changes in any use and long-term use of benzodiazepines were found among groups of women.

\subsection{Concomitant use of benzodiazepines and opioid analgesics}

Rates of opioid analgesics use among patients who were prescribed benzodiazepines in 2003 and 2010 are shown in Table 1. Among patients who were prescribed benzodiazepines long-term in 2003 and 2010, any use of opioids increased from $52.0 \%$ $(50.1-53.9 \%)$ to $63.1 \%(61.8-64.4 \%)$, whereas long-term use of opioids rose from $33.3 \%(31.5-35.1 \%)$ to $46.6 \%(45.2-47.9 \%)$. To 
Age-adjusted and age-specific prevalence of any and long-term benzodiazepine use among men with PTSD for 2003-2010.

$\mathrm{N} \%$ (95\% confidence interval)

\begin{tabular}{|c|c|c|c|c|c|c|c|c|c|c|c|c|}
\hline \multirow[b]{2}{*}{ Any use } & \multicolumn{2}{|l|}{$\overline{\mathrm{All}^{\mathrm{a}}}$} & \multicolumn{2}{|c|}{ Ages $<35^{b, c}$} & \multicolumn{2}{|c|}{ Ages $35-44^{\mathrm{b}}$} & \multicolumn{2}{|c|}{ Ages 45-54 } & \multicolumn{2}{|c|}{ Ages $55-64^{\mathrm{b}, \mathrm{c}}$} & \multicolumn{2}{|c|}{ Ages $\geq 65$} \\
\hline & & & & & & & & & & & & \\
\hline 2003 & 15,337 & $25.0(24.4-25.7)$ & 429 & $17.0(13.4-20.6)$ & 950 & $21.9(19.3-25.5)$ & 5101 & $25.6(24.4-26.8)$ & 6949 & $25.6(24.6-26.6)$ & 1908 & $25.3(23.3-27.2)$ \\
\hline 2004 & 17,039 & $25.1(24.4-25.7)$ & 520 & $17.1(13.9-20.4)$ & 1133 & $24.1(21.6-26.6)$ & 4128 & $26.6(25.2-27.9)$ & 9232 & $25.4(24.6-26.3)$ & 2026 & $23.3(21.5-25.1)$ \\
\hline 2005 & 18,598 & $25.3(24.7-25.9)$ & 966 & $16.7(14.3-19.0)$ & 1310 & $22.7(20.4-24.9)$ & 3256 & $28.2(26.6-29.7)$ & 10856 & $25.8(24.9-26.6)$ & 2210 & $24.7(22.9-26.5)$ \\
\hline 2006 & 18,877 & $26.0(25.4-26.6)$ & 1259 & $17.6(15.4-19.7)$ & 1487 & $24.5(22.4-26.7)$ & 2546 & $28.4(26.7-30.2)$ & 11352 & $27.1(26.2-27.9)$ & 2233 & $23.8(22.0-25.5)$ \\
\hline 2007 & 20,914 & $26.7(26.1-27.3)$ & 1831 & $20.6(18.8-22.5)$ & 1729 & $24.8(22.7-26.8)$ & 2579 & $29.0(27.3-30.8)$ & 12112 & $27.9(27.0-28.6)$ & 2663 & $24.4(22.8-26.0)$ \\
\hline 2008 & 23,702 & $26.3(25.7-26.8)$ & 2786 & $21.1(19.6-22.6)$ & 2023 & $27.0(25.1-29.0)$ & 2750 & $27.2(25.5-28.8)$ & 12988 & $27.8(27.0-28.6)$ & 3155 & $23.2(21.7-24.6)$ \\
\hline 2009 & 25,503 & $27.3(26.8-27.8)$ & 3572 & $22.3(20.9-23.6)$ & 2331 & $27.6(25.8-29.4)$ & 2856 & $29.4(27.7-31.0)$ & 13092 & $28.8(28.0-29.5)$ & 3651 & $24.8(23.4-26.2)$ \\
\hline 2010 & 28,634 & $26.8(26.2-27.3)$ & 4597 & $20.9(19.7-22.1)$ & 2839 & $26.1(24.4-27.7)$ & 3187 & $28.2(26.6-29.7)$ & 13235 & $29.4(28.6-30.2)$ & 4776 & $24.0(22.8-25.2)$ \\
\hline \multicolumn{13}{|c|}{ Long-term use ${ }^{\mathrm{d}}$} \\
\hline 2003 & 15,337 & $15.4(14.8-15.9)$ & 429 & $7.7(5.2-10.2)$ & 950 & $12.6(10.5-14.7)$ & 5101 & $15.9(14.9-16.7)$ & 6949 & $15.8(14.9-16.7)$ & 1908 & $16.6(14.9-18.3)$ \\
\hline 2004 & 17,039 & $15.7(15.2-16.2)$ & 520 & $5.8(3.8-7.8)$ & 1133 & $13.9(11.8-15.9)$ & 4128 & $16.5(15.4-17.6)$ & 9232 & $16.4(15.6-17.2)$ & 2026 & $15.8(14.2-17.4)$ \\
\hline 2005 & 18,598 & $15.6(15.1-16.1)$ & 966 & $4.9(3.5-6.2)$ & 1310 & $12.4(10.7-14.2)$ & 3256 & $17.3(16.0-18.6)$ & 10856 & $16.6(15.9-17.3)$ & 2210 & $16.2(14.7-17.7)$ \\
\hline 2006 & 18,877 & $16.1(15.5-16.6)$ & 1259 & $5.6(4.4-6.9)$ & 1487 & $12.3(10.6-14.0)$ & 2546 & $17.7(16.2-19.2)$ & 11352 & $17.6(16.9-18.3)$ & 2233 & $16.0(14.5-17.5)$ \\
\hline 2007 & 20,914 & $16.4(15.9-16.9)$ & 1831 & $7.6(6.4-8.9)$ & 1729 & $12.5(10.9-14.1)$ & 2579 & $18.1(16.6-19.6)$ & 12112 & $18.2(17.5-18.9)$ & 2663 & $15.9(14.5-17.3)$ \\
\hline 2008 & 23,702 & $16.0(15.5-16.5)$ & 2786 & $8.0(7.0-9.1)$ & 2023 & $13.3(11.9-14.8)$ & 2750 & $15.9(14.6-17.3)$ & 12988 & $18.3(17.7-19.0)$ & 3155 & $15.4(14.2-16.7)$ \\
\hline 2009 & 25,503 & $16.9(16.4-17.3)$ & 3572 & $9.2(8.2-10.1)$ & 2331 & $14.1(12.7-15.5)$ & 2856 & $17.6(16.2-19.0)$ & 13092 & $19.2(18.6-19.9)$ & 3651 & $16.8(15.6-18.1)$ \\
\hline 2010 & 28,634 & $16.4(16.0-16.9)$ & 4597 & $7.7(6.9-8.5)$ & 2839 & $13.5(12.2-14.7)$ & 3187 & $17.1(15.8-18.4)$ & 13235 & $19.8(19.1-20.5)$ & 4776 & $16.2(15.1-17.2)$ \\
\hline
\end{tabular}

a Adjusted for age (continuous).

b Significant linear increase in any benzodiazepine use within age group at $p$-value $\leq 0.05$ adjusted for medical and psychiatric comorbidity.

c Significant linear increase in long-term benzodiazepine use within age group at $p$-value $\leq 0.05$ adjusted for medical and psychiatric comorbidity.

${ }^{\mathrm{d}}$ Long-term use defined as >90 days with prescribed doses in the fiscal year.

Table 4

Age-adjusted and age-specific prevalence of any and long-term benzodiazepine use among women with PTSD for 2003-2010.

\begin{tabular}{|c|c|c|c|c|c|c|c|c|c|c|c|c|}
\hline \multirow[b]{3}{*}{ Any use } & \multicolumn{12}{|c|}{ N\% (95\% confidence interval) } \\
\hline & \multicolumn{2}{|l|}{$\mathrm{All}^{\mathrm{a}}$} & \multicolumn{2}{|c|}{ Ages $<35^{\mathrm{b}, \mathrm{c}}$} & \multicolumn{2}{|c|}{ Ages $35-44^{\mathrm{b}, \mathrm{c}}$} & \multicolumn{2}{|c|}{ Ages $45-54^{\mathrm{b}, \mathrm{c}}$} & \multicolumn{2}{|c|}{ Ages $55-64^{\mathrm{b}, \mathrm{c}}$} & \multicolumn{2}{|c|}{ Ages $\geq 65$} \\
\hline & & & & & & & & & & & & \\
\hline 2003 & 1540 & $31.2(28.9-33.5)$ & 255 & $23.1(17.9-28.3)$ & 434 & $30.6(26.3-35.0)$ & 601 & $34.6(30.8-38.4)$ & 210 & $34.3(27.8-40.8)$ & 40 & $17.5(5.2-29.8)$ \\
\hline 2004 & 1781 & $33.1(30.9-35.3)$ & 297 & $26.6(21.5-31.7)$ & 464 & $33.8(33.8-38.2)$ & 706 & $36.0(32.4-39.5)$ & 266 & $32.3(26.7-38.0)$ & 48 & $27.1(14.0-40.1)$ \\
\hline 2005 & 1903 & $33.1(31.0-35.3)$ & 347 & $22.5(18.1-26.9)$ & 462 & $33.8(29.4-38.1)$ & 731 & $37.8(34.2-41.3)$ & 302 & $33.8(28.4-39.1)$ & 61 & $29.5(17.7-41.3)$ \\
\hline 2006 & 1982 & $33.4(31.3-35.5)$ & 375 & $25.6(21.2-30.0)$ & 473 & $33.6(29.3-37.8)$ & 742 & $37.5(34.2-41.3)$ & 327 & $31.5(26.4-36.6)$ & 65 & $38.5(26.3-50.6)$ \\
\hline 2007 & 2216 & $36.2(34.2-38.2)$ & 402 & $31.3(26.8-35.9)$ & 482 & $34.9(30.6-39.1)$ & 829 & $37.6(34.3-40.9)$ & 423 & $38.3(33.6-42.9)$ & 80 & $45.0(33.9-56.1)$ \\
\hline 2008 & 2533 & $37.1(35.2-39.0)$ & 519 & $26.2(22.4-30.0)$ & 520 & $36.3(32.2-40.5)$ & 924 & $43.4(40.2-46.6)$ & 466 & $38.8(34.4-43.3)$ & 104 & $31.7(22.6-40.8)$ \\
\hline 2009 & 2747 & $37.1(35.3-38.9)$ & 607 & $29.3(25.7-33.0)$ & 567 & $35.4(31.5-39.4)$ & 880 & $43.4(40.1-46.7)$ & 578 & $38.2(34.3-42.2)$ & 115 & $33.9(25.1-42.7)$ \\
\hline 2010 & 3263 & $38.8(37.1-40.5)$ & 764 & $28.4(25.2-31.6)$ & 659 & $41.7(38.0-45.5)$ & 996 & $42.8(39.7-45.8)$ & 695 & $42.4(38.8-46.1)$ & 149 & $35.6(27.8-43.3)$ \\
\hline \multicolumn{13}{|c|}{ Long-term use ${ }^{d}$} \\
\hline 2003 & 1540 & $17.8(15.9-19.8)$ & 255 & $9.8(6.1-13.5)$ & 434 & $15.9(12.4-19.4)$ & 601 & $22.7(19.6-26.3)$ & 210 & $19.5(14.1-24.9)$ & 40 & $5.0(-2.1-12.1)$ \\
\hline 2004 & 1781 & $17.9(16.1-19.7)$ & 297 & $9.1(5.8-12.4)$ & 464 & $17.5(14.0-20.9)$ & 706 & $22.7(19.6-25.8)$ & 266 & $16.5(12.0-21.0)$ & 48 & $16.7(5.7-27.6)$ \\
\hline 2005 & 1903 & $17.4(15.7-19.1)$ & 347 & $8.4(5.4-11.3)$ & 462 & $17.3(13.9-20.8)$ & 731 & $21.6(18.6-24.6)$ & 302 & $18.9(14.4-23.3)$ & 61 & $14.8(5.6-23.9)$ \\
\hline 2006 & 1982 & $18.9(17.2-20.6)$ & 375 & $10.4(7.3-13.5)$ & 473 & $19.7(16.1-23.3)$ & 742 & $21.6(18.6-24.5)$ & 327 & $21.4(16.9-25.9)$ & 65 & $21.5(11.3-31.8)$ \\
\hline 2007 & 2216 & $19.5(17.8-21.1)$ & 402 & $10.7(7.7-13.7)$ & 482 & $19.7(16.1-23.3)$ & 829 & $22.9(20.1-25.8)$ & 423 & $23.2(19.1-27.2)$ & 80 & $23.8(14.2-33.3)$ \\
\hline 2008 & 2533 & $21.0(19.4-22.6)$ & 519 & $11.6(8.8-14.3)$ & 520 & $19.8(16.4-23.2)$ & 924 & $26.3(23.5-29.1)$ & 466 & $24.5(20.5-28.4)$ & 104 & $16.3(9.1-23.6)$ \\
\hline 2009 & 2747 & $22.4(20.8-23.9)$ & 607 & $12.9(10.2-15.5)$ & 567 & $21.5(18.1-24.9)$ & 880 & $28.5(25.5-31.5)$ & 578 & $25.1(21.5-28.6)$ & 115 & $18.3(11.1-25.4)$ \\
\hline 2010 & 3263 & $22.6(21.2-24.0)$ & 764 & $12.4(10.1-14.8)$ & 659 & $23.8(20.6-27.1)$ & 996 & $28.2(25.4-31.0)$ & 695 & $26.3(23.0-29.6)$ & 149 & $18.1(11.9-24.4)$ \\
\hline
\end{tabular}

a Adjusted for age (continuous).

Significant linear increase in any benzodiazepine use within age group at $p$-value $\leq 0.05$ adjusted for medical and psychiatric comorbidity.

c Significant linear increase in long-term benzodiazepine use within age group at $p$-value $\leq 0.05$ adjusted for medical and psychiatric comorbidity.

${ }^{\mathrm{d}}$ Long-term use defined as $>90$ days with prescribed doses in the fiscal year. 
Table 5

Trends in any and long-term benzodiazepine use among men and women with PTSD across fiscal years, 2003-2010.

\begin{tabular}{|c|c|c|c|c|c|c|c|c|}
\hline & \multicolumn{4}{|c|}{ Any benzodiazepine use } & \multicolumn{4}{|c|}{ Long-term ${ }^{\mathrm{a}}$ benzodiazepine use } \\
\hline & \multicolumn{2}{|l|}{ Men } & \multirow{2}{*}{$\begin{array}{l}\text { Women } \\
\text { OR }\end{array}$} & \multirow[b]{2}{*}{$(95 \% \mathrm{CI})$} & \multicolumn{2}{|l|}{ Men } & \multicolumn{2}{|c|}{ Women } \\
\hline & $\overline{\mathrm{OR}}$ & $(95 \% \mathrm{CI})$ & & & $\overline{\mathrm{OR}}$ & $(95 \% \mathrm{CI})$ & $\overline{\mathrm{OR}}$ & $(95 \% \mathrm{CI})$ \\
\hline \multicolumn{9}{|l|}{ Main effects } \\
\hline Year & 1.02 & $(1.00-1.05)^{*}$ & 1.00 & $(0.96-1.05)$ & 1.03 & $(1.00-1.06)$ & 1.04 & $(0.97-1.11)$ \\
\hline \multicolumn{9}{|l|}{ Age (years) } \\
\hline$<35$ & 1.00 & (ref.) & 1.00 & (ref.) & 1.00 & (ref.) & 1.00 & (ref.) \\
\hline $35-44$ & 1.40 & $(1.18-1.66)^{* * *}$ & 1.30 & $(1.01-1.68)^{*}$ & 2.41 & $(1.88-3.07)^{* * *}$ & 1.97 & $(1.38-2.81)^{* * *}$ \\
\hline $45-54$ & 1.83 & $(1.58-2.12)^{* * *}$ & 1.49 & $(1.18-1.89)^{* * *}$ & 3.43 & $(2.76-4.26)^{* * *}$ & 2.72 & $(1.95-3.80)^{* * *}$ \\
\hline $55-64$ & 1.71 & $(1.49-1.97)^{* * *}$ & 1.24 & $(0.94-1.63)$ & 3.19 & $(2.58-3.94)^{* * *}$ & 2.07 & $(1.42-3.02)^{* * * *}$ \\
\hline$\geq 65$ & 1.45 & $(1.23-1.70)^{* * *}$ & & & 2.92 & $(2.32-3.66)^{* * *}$ & & \\
\hline \multicolumn{9}{|c|}{ Medical comorbidity (Charlson score) } \\
\hline 0 & 1.00 & (ref.) & 1.00 & (ref.) & 1.00 & (ref.) & 1.00 & (ref.) \\
\hline 1 & 1.15 & $(1.08-1.23)^{* * *}$ & 1.06 & $(0.87-1.29)$ & 1.14 & $(1.06-1.24)^{* *}$ & 0.96 & $(0.76-1.20)$ \\
\hline$\geq 2$ & 1.35 & $(1.26-1.45)^{* * *}$ & 1.53 & $(1.18-1.98)^{* *}$ & 1.20 & $(1.11-1.31)^{* * *}$ & 1.47 & $(1.08-1.99)^{*}$ \\
\hline \multicolumn{9}{|c|}{ Psychiatric comorbidity (count of mental health disorders) } \\
\hline None & 1.00 & (ref.) & & & 1.00 & (ref.) & 1.00 & (ref.) \\
\hline 1 & 1.44 & $(1.35-1.54)^{* * *}$ & 1.57 & $(1.26-1.97)^{* * *}$ & 1.36 & $(1.27-1.47)^{* * *}$ & 1.71 & $(1.27-2.31)^{* * *}$ \\
\hline$\geq 2$ & 2.96 & $(2.73-3.21)^{* * *}$ & 3.34 & $(2.61-4.28)^{* * *}$ & 2.74 & $(2.49-3.01)^{* * *}$ & 3.59 & $(2.62-4.93)^{* * *}$ \\
\hline \multicolumn{9}{|l|}{ SUD comorbidity (category) } \\
\hline None & 1.00 & (ref.) & 1.00 & (ref.) & 1.00 & (ref.) & 1.00 & (ref.) \\
\hline Alcohol only & 0.62 & $(0.56-0.70)^{* * *}$ & 0.61 & $(0.44-0.86)^{* *}$ & 0.51 & $(0.45-0.57)^{* * *}$ & 0.71 & $(0.46-1.08)$ \\
\hline Drug only & 1.02 & $(0.89-1.16)$ & 1.45 & $(0.96-2.17)$ & 1.02 & $(0.88-1.20)$ & 0.98 & $(0.61-1.57)$ \\
\hline Alcohol and drug & 0.56 & $(0.50-0.63)^{* * *}$ & 0.91 & $(0.64-1.29)$ & 0.42 & $(0.36-0.49)^{* * *}$ & 0.74 & $(0.48-1.15)$ \\
\hline \multicolumn{9}{|l|}{ Linear trends (across years) } \\
\hline \multicolumn{9}{|l|}{ Age $\times$ year } \\
\hline$<35$ & 1.00 & (ref.) & 1.00 & (ref.) & 1.00 & (ref.) & 1.00 & (ref.) \\
\hline $35-44$ & 0.98 & $(0.96-1.01)$ & 1.02 & $(0.97-1.06)$ & 0.95 & $(0.91-0.98)^{* *}$ & 1.00 & $(0.94-1.06)$ \\
\hline $45-54$ & 0.95 & $(0.93-0.97)^{* * *}$ & 1.02 & $(0.98-1.06)$ & 0.94 & $(0.90-0.97)^{* * *}$ & 0.99 & $(0.93-1.04)$ \\
\hline $55-64$ & 0.98 & $(0.95-1.00)^{*}$ & 1.02 & $(0.97-1.01)$ & 0.97 & $(0.94-1.01)$ & 1.00 & $(0.94-1.07)$ \\
\hline$\geq 65$ & 0.96 & $(0.94-0.99)^{* *}$ & & & 0.95 & $(0.92-0.99)^{* *}$ & & \\
\hline \multicolumn{9}{|c|}{ Medical comorbidity (Charlson score) $\times$ year } \\
\hline 0 & 1.00 & (ref.) & 1.00 & (ref.) & 1.00 & (ref.) & 1.00 & (ref.) \\
\hline 1 & 1.00 & $(0.98-1.01)$ & 1.02 & $(0.98-1.05)$ & 1.00 & $(0.99-1.02)$ & 1.04 & $(1.00-1.09)^{*}$ \\
\hline$\geq 2$ & 0.99 & $(0.98-1.00)$ & 0.98 & $(0.94-1.03)$ & 1.00 & $(0.98-1.01)$ & 0.99 & $(0.94-1.05)$ \\
\hline \multicolumn{9}{|c|}{ Psychiatric comorbidity (count of mental health disorders) $\times$ year } \\
\hline None & 1.00 & (ref.) & 1.00 & (ref.) & 1.00 & (ref.) & 1.00 & (ref.) \\
\hline 1 & 1.04 & $(1.03-1.05)^{* * *}$ & 1.04 & $(1.00-1.08)$ & 1.05 & $(1.03-1.06)^{* * *}$ & 1.03 & $(0.98-1.09)$ \\
\hline$\geq 2$ & 1.04 & $(1.03-1.06)^{* * *}$ & 1.04 & $(1.00-1.09)$ & 1.05 & $(1.03-1.07)^{* * *}$ & 1.02 & $(0.97-1.08)$ \\
\hline \multicolumn{9}{|l|}{ Substance use comorbidity $\times$ year } \\
\hline None & 1.00 & (ref.) & 1.00 & (ref.) & 1.00 & (ref.) & 1.00 & (ref.) \\
\hline Alcohol use disorder only & 1.02 & $(1.00-1.04)^{*}$ & 1.02 & $(0.96-1.09)$ & 1.02 & $(1.00-1.05)^{*}$ & 0.99 & $(0.92-1.06)$ \\
\hline Drug use disorder only & 1.03 & $(0.99-1.04)$ & 0.98 & $(0.91-1.05)$ & 1.01 & $(0.99-1.04)$ & 1.04 & $(0.96-1.12)$ \\
\hline Alcohol and drug use disorder & 1.03 & $(1.01-1.05)^{* *}$ & 0.96 & $(0.90-1.03)$ & 1.01 & $(0.98-1.04)$ & 0.97 & $(0.90-1.05)$ \\
\hline $\begin{aligned} \text { CI, confidence interval; OR, odds ra } \\
\text { a } \\
{ }^{*} \text { Long-term use defined as }>90 \\
<0.05 . \\
\text { * }^{* *}<0.01 . \\
{ }_{* * *}<0.001 .\end{aligned}$ & $\mathrm{h} \mathrm{p}$ & doses in the & & & & & & \\
\hline
\end{tabular}

determine the likelihood of patients receiving opioids and benzodiazepines concomitantly, we reviewed the distribution of patients with both opioid and benzodiazepine prescriptions. In fiscal year $2010,87.9 \%$ of patients who were co-prescribed any opioid and benzodiazepine, and $99.7 \%$ of patients co-prescribed long-term use of opioids and benzodiazepines, had overlapping prescriptions ( $\geq 1$ day). The mean days of overlap was 141.1 ( $S D=126.2$ ) among patients who were prescribed both opioids and benzodiazepines and 238.3 ( $\mathrm{SD}=97.9$ ) among patients prescribed both opioids and benzodiazepines long-term.

\section{Discussion}

Despite clinical guidelines and research that caution against the use of benzodiazepines, adjusted analyses showed modest increases over the 8-year period in the percent of patients with any use and long-term use of benzodiazepines among both women and men with PTSD. While a recent study (Lund et al., 2011) reported an overall decline in any benzodiazepine use from 37\% in 1999 to $31 \%$ in 2009 among VA patients with PTSD, our results suggest that differential increases in use are seen by gender, age, and certain high risk behaviors among patients in VISN 20 with PTSD. Of note, the present study showed an increase in any benzodiazepine use from $31 \%$ in 2003 to $39 \%$ in 2010 among women patients with PTSD. The absolute number of patients with any or long term use approximately doubled, consistent with the growth in the number of veterans with PTSD treated in VA over these years.

Our results further suggested greater increases in long-term benzodiazepine use among men younger than 35 and aged 55-64 and surprisingly, among women of all but the oldest age groups. As benzodiazepines are often prescribed because of their ability to provide rapid relief from acute distress, high rates of distress reported among men and women returning from OEF/OIF may account for the increase in long-term use among those under 35 (Seal et al., 2007). Results that appear to support this explanation show greater increases in long-term benzodiazepine use among men with comorbid psychiatric disorders than among men with PTSD only and among men with comorbid alcohol use disorders than among men without substance use disorders. However, this study was unable to identify factors that accounted for the 
increase in long-term use of benzodiazepines among women. Further research on the causes or factors associated with the rise in long-term use of benzodiazepines may be needed to more effectively manage their use among men, and especially women, treated for PTSD.

Comparisons to previous studies of benzodiazepine use among VA and non-VA patients with PTSD are difficult, because rates were reported in aggregate with anxiolytics and sedative-hypnotic use or overall without consideration of gender (Harpaz-Rotem et al., 2008; Lund et al., 2011; Mohamed and Rosenheck, 2008). However, overall rates of any use (23-53\%) and long-term use (32\%) of benzodiazepines are generally higher among patients with psychiatric disorders than without such disorders (2-6\%; Liu et al., 2010; Lund et al., 2011; Valenstein et al., 2004; Yang et al., 2008). Thus, it is not surprising that the estimates of any and long-term benzodiazepine use among patients diagnosed with PTSD are considerably higher than rates of any and long-term benzodiazepine use reported in population based studies.

Potential risks in patients who misuse alcohol resulted in recommendations to avoid long-term use of benzodiazepines among patients with alcohol use disorders (Lader, 2011), yet in fiscal year 2010, 1 in 10 long-term users of benzodiazepines in this sample had a comorbid alcohol use disorder. The percentage of the sample at risk due to alcohol use likely is greater than $10 \%$ given that unhealthy alcohol use is more prevalent than alcohol use disorders (Saitz, 2005). This may be especially relevant to younger veterans and service personnel who served in OEF/OIF, as the prevalence of unhealthy alcohol use and binge drinking among this subpopulation is approximately 22 and 49\%, respectively (Jacobson et al., 2008; Hawkins et al., 2010). Thus, there remains a need to educate providers as to potential risks of long-term use among patients with documented alcohol related problems.

Perhaps, the most striking result of the study was the high percentage $(47 \%)$ of long-term benzodiazepine users who also received opioid medications long-term in the same year. Prior cross-sectional studies have suggested an association between benzodiazepine and opioid use (Morasco et al., 2010), but few published studies have examined co-prescription of these medications in a sample of patients with PTSD. The concomitant use of these medications poses greater risks, as suggested by recent national data on the involvement of opioids and benzodiazepines in poisoning deaths (Warner et al., 2009) and emergency department visits (Substance Abuse and Mental Health Services Administration, 2011).

The increase in prescriptions among high risk groups suggests a need to develop efficient strategies to systematically screen for and monitor patients who are prescribed benzodiazepines long-term. Such strategies could identify patients at risk for adverse outcomes based on established criteria (e.g., suicide risk, substance use disorders or problematic use of alcohol or drugs, concomitant use of opioids or other medications, age) and facilitate periodic follow-up to assess and evaluate the risks and benefits of long-term benzodiazepine therapy. As a substantial minority of patients with PTSD is routinely prescribed benzodiazepines and information about their efficacy or adverse events in this population is largely anecdotal at present, randomized controlled trials are needed to evaluate the long-term efficacy and safety of their use (Tyrer, 2010).

Our results showed little change in the mean daily dose and days' supply of benzodiazepines from 2003 to 2008 (Table 3) among patients with any and long-term use. Although it is reassuring that most patients were prescribed a dose within the therapeutic range for benzodiazepines ( $0-40 \mathrm{mg} /$ day), $42 \%$ of patients received $>180$ days' supply of benzodiazepines, a duration of benzodiazepine therapy that is known to increase the risk of physical dependence and complications associated with discontinuation, even on doses within the therapeutic range and for patients without substance use disorders (Lader, 1999, 2011; Rickels et al., 1983). Due to increased risk of adverse outcomes among older patients who are prescribed benzodiazepines, a large subset of VA patients may need assistance in tapering medications and managing withdrawal symptoms within the next decade, as over two-thirds of the patients in this study were 55 or older in fiscal year 2010.

This study has several limitations. Patients in this study were treated in only one of 21 VISNs in the VA, and thus results may not generalize to men and women veterans enrolled in VA care nationally. Results also may not generalize to Veteran patients or non-Veteran patients who receive health care outside of VA. Prescription data were limited to VA outpatient pharmacy records and would not reflect prescriptions from non-VA providers. Data reflect availability of prescribed benzodiazepines and opioids, but no data were available on actual use and whether it was as prescribed. Estimates of diazepam dose equivalents presented in this study were based on sources in the literature and thus may be imprecise. Despite clinical guidelines that discourage long-term use of benzodiazepines, this study was not able to determine if such prescription patterns were inappropriate or if there were indications for long-term use. Although our models adjusted for important demographic and clinical covariates such as age, gender, and medical, psychiatric and substance use disorder comorbidity, our results may have been confounded by other variables not measured.

\section{Conclusion}

Despite nearly a decade of clinical guidelines consistently cautioning against the use of benzodiazepines for the management of PTSD symptoms, the adjusted annual prevalence of long-term benzodiazepine use increased marginally among men and moderately among women with PTSD from 2003 to 2010. In 2010, nearly 1 in 6 men and 1 in 4 women with PTSD in VISN 20 were prescribed benzodiazepines long-term. Of note, nearly half of long-term benzodiazepine users also received opioid analgesics long-term in the same year. Since use of benzodiazepines among VA patients with PTSD is so widespread, further research on their efficacy and the likelihood of adverse outcomes in this population is warranted to evaluate the harm and benefit of prescribing benzodiazepines long-term. Results also suggest efficient monitoring strategies are needed to identify and monitor patients at greater risk for adverse outcomes based on concomitant use of benzodiazepines and opioid analgesics or other risk factors. In particular, the frequent concomitant prescribing of benzodiazepines and opioids deserves further study in regard to the neuropharmacology of this combination and its effects on chronic pain as well as its safety.

\section{Role of funding source}

This material is the result of work supported by resources from the VA Puget Sound Health Care System, Center of Excellence in Substance Abuse Treatment \& Education, Seattle, WA. Supporting organizations had no further role in study design; in the collection, analysis and interpretation of data; in the writing of the report; or in the decision to submit the paper for publication. The views expressed in this article are those of the authors and do not necessarily reflect the position or policy of the Department of Veterans Affairs or the University of Washington.

\section{Contributors}

All authors contributed to the conceptualization of the manuscript. Dr. Hawkins prepared the first draft of the manuscript and Ms. Malte performed statistical analyses. Dr. Imel, Dr. Saxon, Dr. Kivlahan and Ms. Malte reviewed and contributed to all 
subsequent drafts of the manuscript. All authors have approved the final manuscript.

\section{Conflict of interest}

All of the authors report no conflict of interest.

\section{Acknowledgement}

Preliminary data were presented at the National Veterans Health Administration Annual Mental Health Care Conference, Baltimore, August 2011.

\section{References}

American Psychiatric Association, 2004. Practice Guideline for the Treatment of Patients with Acute Stress Disorder and Posttraumatic Stress Disorder. American Psychiatric Association, Arlington.

Baldwin, D.S., Anderson, I.M., Nutt, D.J., Bandelow, B., Bond, A., Davidson, J.R., den Boer, J.A., 2005. Evidence-based guidelines for the pharmacological treatment of anxiety disorders: recommendations from the British Association for Psychopharmacology. J. Psychopharmacol. 19, 567-596.

Barker, M.J., Greenwood, K.M., Jackson, M., Crowe, S.F., 2004. Cognitive effects of long-term benzodiazepine use: a meta-analysis. CNS Drugs 18, 37-48.

Bohnert, A.S., Valenstein, M., Bair, M.J., Ganoczy, D., McCarthy, J.F., Ilgen, M.A., Blow, F.C., 2011. Association between opioid prescribing patterns and opioid overdoserelated deaths. JAMA 305, 1315-1321.

Boscarino, J.A., 2006. Posttraumatic stress disorder and mortality among U.S. Army Veterans 30 years after military service. Ann. Epidemiol. 16, 248-256.

Charlson, M.E., Pompei, P., Ales, K.L., MacKenzie, C.R., 1987. A new method of classifying prognostic comorbidity in longitudinal studies: development and validation. J. Chronic Dis. 40, 373-383.

Chouinard, G., 2004. Issues in the clinical use of benzodiazepines: potency, withdrawal, and rebound. J. Clin. Psychiatry 65 (Suppl. 5), 7-12.

Cumming, R.G., Le Couteur, D.G., 2003. Benzodiazepines and risk of hip fractures in older people: a review of the evidence. CNS Drugs 17, 825-837.

Cunningham, C.M., Hanley, G.E., Morgan, S., 2010. Patterns in the use of benzodiazepines in British Columbia: examining the impact of increasing research and guideline cautions against long-term use. Health Policy 97, 122-129.

Davydow, D.S., Gifford, J.M., Desai, S.V., Needham, D.M., Bienvenu, O.J., 2008. Posttraumatic stress disorder in general intensive care unit survivors: a systematic review. Gen. Hosp. Psychiatry 30, 421-434.

Edlund, M.J., Martin, B.C., Devries, A., Fan, M.Y., Braden, J.B., Sullivan, M.D., 2010 Trends in use of opioids for chronic noncancer pain among individuals with mental health and substance use disorders: the TROUP study. Clin. J. Pain 26, $1-8$.

Edlund, M.J., Steffick, D., Hudson, T., Harris, K.M., Sullivan, M., 2007. Risk factors for clinically recognized opioid abuse and dependence among veterans using opioids for chronic non-cancer pain. Pain 129, 355-362.

Galanter, M., Kleber, H., 2008. The American Psychiatric Publishing Textbook of Substance Abuse Treatment, 4th ed. American Psychiatric Publishing. Inc., Arlington.

Gelpin, E., Bonne, O., Peri, T., Brandes, D., Shalev, A.Y., 1996. Treatment of recent trauma survivors with benzodiazepines: a prospective study. J. Clin. Psychiatry 57, 390-394.

Harpaz-Rotem, I., Rosenheck, R.A., Mohamed, S., Desai, R.A., 2008. Pharmacologic treatment of posttraumatic stress disorder among privately insured Americans. Psychiatr. Serv. 59, 1184-1190.

Hawkins, E.J., Lapham, G.T., Kivlahan, D.R., Bradley, K.A., 2010. Recognition and management of alcohol misuse in OEF/OIF and other veterans in the VA: a cross-sectional study. Drug Alcohol Depend. 109, 147-153.

Hoffman, E.J., Mathew, S.J., 2008. Anxiety disorders: a comprehensive review of pharmacotherapies. Mt. Sinai J. Med. 75, 248-262.

Jacobsen, L.K., Southwick, S.M., Kosten, T.R., 2001. Substance use disorders in patients with posttraumatic stress disorder: a review of the literature. Am. J Psychiatry 158, 1184-1190.

Jacobson, I.G., Ryan, M.A., Hooper, T.I., Smith, T.C., Amoroso, P.J., Boyko, E.J., Gackstetter, G.D., Wells, T.S., Bell, N.S., 2008. Alcohol use and alcohol-related problems before and after military combat deployment. JAMA 300, 663-675.

Keane, T.M., Kaloupek, D.G., 1997. Comorbid psychiatric disorders in PTSD. Implications for research. Ann. N. Y. Acad. Sci. 821, 24-34.

Kressin, N.R., Chang, B.H., Hendricks, A., Kazis, L.E., 2003. Agreement between administrative data and patients' self-reports of race/ethnicity. Am. J. Public Health 93 1734-2179.

Lader, M., 2011. Benzodiazepines revisited - will we ever learn? Addiction, doi:10.1111/j.1360-0443.2011.03563.x(Epub, 17 October 2011).

Lader, M.H., 1999. Limitations on the use of benzodiazepines in anxiety and insomnia: are they justified? Eur. Neuropsychopharmacol. 9 (Suppl. 6), S399-S405.
Lagnaoui, R., Depont, F., Fourrier, A., Abouelfath, A., Begaud, B., Verdoux, H., Moore, N., 2004. Patterns and correlates of benzodiazepine use in the French general population. Eur. J. Clin. Pharmacol. 60, 523-529.

Liu, X., Ye, W., Watson, P., Tepper, P., 2010. Use of benzodiazepines, hypnotics, and anxiolytics in major depressive disorder: association with chronic pain diseases. J. Nerv. Ment. Dis. 198, 544-550.

Longo, L.P., Johnson, B., 2000. Addiction. Part I. Benzodiazepines - side effects, abuse risk and alternatives. Am. Fam. Physician 61, 2121-2128.

Lund, B.C., Bernardy, N.C., Alexander, B., Friedman, M.J., 2011. Declining benzodiazepine use in veterans with posttraumatic stress disorder. J. Clin. Psychiatry, http://www.psychiatrist.com/privatepdf/oap/10m06775.pdf [Epub ahead of print].

Mohamed, S., Rosenheck, R.A., 2008. Pharmacotherapy of PTSD in the U.S. Department of Veterans Affairs: diagnostic- and symptom-guided drug selection. J. Clin. Psychiatry 69, 959-965.

Morasco, B.J., Duckart, J.P., Carr, T.P., Deyo, R.A., Dobscha, S.K., 2010. Clinical characteristics of veterans prescribed high doses of opioid medications for chronic non-cancer pain. Pain 151, 625-632.

Petitjean, S., Ladewig, D., Meier, C.R., Amrein, R., Wiesbeck, G.A., 2007. Benzodiazepine prescribing to the Swiss adult population: results from a national survey of community pharmacies. Int. Clin. Psychopharmacol. 22, 292-298.

Petrakis, I.L., Rosenheck, R., Desai, R., 2011. Substance use comorbidity among veterans with posttraumatic stress disorder and other psychiatric illness. Am. J. Addict. 20, 185-189.

Pfeiffer, P.N., Ganoczy, D., Ilgen, M., Zivin, K., Valenstein, M., 2009. Comorbid anxiety as a suicide risk factor among depressed veterans. Depress. Anxiety 26, 752-757.

Physicians' Desk Reference, 2011. Physicians' Desk Reference, 65th ed. New Jersey.

Quan, H., Sundararajan, V., Halfon, P., Fong, A., Burnand, B., Luthi, J.C., Saunders, L.D., Beck, C.A., Feasby, T.E., Ghali, W.A., 2005. Coding algorithms for defining comorbidities in ICD-9-CM and ICD-10 administrative data. Med. Care 43, 1130-1139.

Rickels, K., Case, W.G., Downing, R.W., Winokur, A., 1983. Long-term diazepam therapy and clinical outcome. JAMA 250, 767-771.

Riemann, D., Perlis, M.L., 2009. The treatments of chronic insomnia: a review of benzodiazepine receptor agonists and psychological and behavioral therapies. Sleep Med. Rev. 13, 205-214.

Saitz, R., 2005. Clinical practice. Unhealthy alcohol use. N. Engl. J. Med. 352, 596-607.

Seal, K.H., Bertenthal, D., Miner, C.R., Sen, S., Marmar, C., 2007. Bringing the war back home: mental health disorders among 103,788 US veterans returning from Iraq and Afghanistan seen at Department of Veterans Affairs facilities. Arch. Intern. Med. 167, 476-482.

Smink, B.E., Egberts, A.C., Lusthof, K.J., Uges, D.R., de Gier, J.J., 2010. The relationship between benzodiazepine use and traffic accidents: a systematic literature review. CNS Drugs 24,639-653.

StataCorp., 2007. Stata Statistical Software: Release Edition 9.0. Stata Corporation, College Station, TX.

Stein, D.J., Ipser, J.C., Seedat, S., 2006. Pharmacotherapy for post traumatic stress disorder (PTSD). Cochrane Database Syst. Rev. (CD002795).

Substance Abuse and Mental Health Services Administration, 2011. Drug Abuse Warning Network, National Estimates of Drug-Related Emergency Department Visits, Rockville, MD. Available from: https://dawninfo.samhsa.gov/default.asp.

Sullivan, M.D., Edlund, M.J., Fan, M.Y., Devries, A., Brennan Braden, J., Martin, B.C. 2008. Trends in use of opioids for non-cancer pain conditions 2000-2005 in commercial and Medicaid insurance plans: the TROUP study. Pain 138, 440-449.

The Management of Substance Use Disorders Working Group, 2010. VA/DOD Clinical Practice Guideline for Management of Post-Traumatic Stress (Version 2.0). Department of Veterans Affairs and the Department of Defense, Washington, DC, Available from: http://www.healthquality.va.gov/ Substance_Use_Disorder_SUD.asp (accessed september 26, 2011).

Tyrer, P., 2010. Benzodiazepine substitution for dependent patients-going with the flow. Addiction 105, 1875-1876.

Valenstein, M., Taylor, K.K., Austin, K., Kales, H.C., McCarthy, J.F., Blow, F.C., 2004. Benzodiazepine use among depressed patients treated in mental health settings. Am. J. Psychiatry 161, 654-661.

van Minnen, A., Arntz, A., Keijsers, G.P., 2002. Prolonged exposure in patients with chronic PTSD: predictors of treatment outcome and dropout. Behav. Res. Ther. 40, 439-457.

Warner, M., Chen, L.H., Makuc, D.M., 2009. Increase in fatal poisonings involving opioid analgesics in the United States, 1999-2006. NCHS Data Brief 1-8.

White, J.M., Irvine, R.J., 1999. Mechanisms of fatal opioid overdose. Addiction 94, 961-972.

Woolcott, J.C., Richardson, K.J., Wiens, M.O., Patel, B., Marin, J., Khan, K.M., Marra, C.A., 2009. Meta-analysis of the impact of 9 medication classes on falls in elderly persons. Arch. Intern. Med. 169, 1952-1960.

Yang, H.W., Simoni-Wastila, L., Zuckerman, I.H., Stuart, B., 2008. Benzodiazepine use and expenditures for Medicare beneficiaries and the implications of Medicare Part D exclusions. Psychiatr. Serv. 59, 384-391.

Zandstra, S.M., Furer, J.W., van de Lisdonk, E.H., van't, H.M., Bor, J.H., van Weel, C., Zitman, F.G., 2002. Different study criteria affect the prevalence of benzodiazepine use. Soc. Psychiatry Psychiatr. Epidemiol. 37, 139-144. 